BUCHRUCKER, Cristian, CARRIZO DE MUÑOZ, Nidia, SÁNCHEZ, Norma Isabel, El eterno retorno de los populismos. Un panorama mundial, latinoamericano y argentino. Prometeo libros, Buenos Aires, 2015, 196 páginas.

Andrés ABRAHAM

Avances del Cesor, V. XIII, No 15, Segundo semestre 2016, pp. 209-212.

ISSNe 2422-6580 / ISSN 1514-3899 - http://web2.rosario-conicet.gov.ar/ojs/index.php/AvancesCesor/index

\title{
BUCHRUCKER, Cristian, CARRIZO DE MUÑOZ, Nidia, SÁNCHEZ, Norma Isabel, El eterno retorno de los populismos. Un panorama mundial, latinoamericano y argentino. Prometeo libros, Buenos Aires, 2015, 196 páginas.
}

\author{
Andrés Abraham \\ Universidad Nacional de Cuyo \\ (Argentina) \\ andresabraham04@gmail.com
}

El eterno retorno de los populismos presenta una serie de reflexiones sobre la relación entre los historiadores y el populismo. Los autores son tres ex compañeros de estudios de la Facultad de Filosofía y Letras de la Universidad Nacional de Cuyo -a quienes la vida académica llevó por distintas instituciones y derroteros temáticos-, que se reencontraron para condensar en este libro algunos aspectos de sus experiencias de vida y de sus trayectorias intelectuales con el objeto de desentrañar la discusión sobre los populismos desde la mirada de la Historia. Procuran brindar con este trabajo una vía exploratoria que permita identificar las disputas académicas en torno al término "populismo", tanto a nivel de su semántica como en relación a los casos históricos concretos para los que suele usarse. Como punto de partida, reconocen que la discusión lleva ya más de cuatro décadas y que suele darse acompañada de desmesuras que no contribuyen a clarificar su utilización. En este marco, los autores reivindican la percepción de los populismos y su persistencia en el tiempo como fenómenos que deben ser analizados y comprendidos en el marco de las sociedades en los que surgen.

El libro está estructurado en cinco capítulos, comenzando con una mirada sobre la discusión teórica y su correlato en el panorama de la historia mundial a cargo de Cristian Buchrucker. Los tres capítulos siguientes -cuya autora es Nidia Carrizo de Muñoz-, pasan revista por los casos históricos que se dieron en el espacio latinoamericano y las discusiones historiográficas en torno a ellos, 
particularmente en Brasil y Argentina. Por último se presenta un singular abordaje de los populismos en la historia argentina, desde la pluma de Norma Sánchez, con el foco puesto en la economía y las políticas de salud.

La obra condensa algunos planteos y análisis publicados por los autores en otras de sus publicaciones anteriores, pero que van acompañados en este volumen de un análisis de las referencias al populismo en los períodos que cada autor trabaja, así como de un rico diálogo intertextual entre los propios autores, y también con otras obras que versan sobre el tema en cuestión.

El primer capítulo apunta a ubicar el debate sobre el populismo en el marco de la historia mundial, a través de una perspectiva históricocomparativa. Parte del cuestionamiento de la corriente mayoritaria que percibe al populismo como una "anomalía", en el marco del debate más amplio sobre el capitalismo y la democracia, señalando la hegemonía liberalconservadora que ha guiado dicho debate.

En una primera parte aborda el debate académico sobre dicho término, afirmando que persiste en su uso la variabilidad de significados, y que no hay para los historiadores una definición a priori, sino que existe una serie de interrogantes -enmarcada en la polémica que la palabra genera según las distintas miradas-. Define a partir de esos interrogantes cuatro ejes de análisis: retórica y propaganda populistas, mentalidad y base social más permeables al populismo, ideología populista y forma de ejercer el poder, y casos históricos de populismo. Entiende Buchrucker que para el historiador la categoría "populismo" debe ceñirse a un sentido determinado, con un alcance espacial y analítico delimitado. Expresa además que el debate de la filosofía política no penetra en el análisis histórico, pero que es necesario determinar el lugar del populismo en el debate historiográfico contemporáneo para identificar las formas de su utilización y su utilidad como categoría de análisis.

En una segunda parte, el autor presenta un análisis de los abordajes historiográficos a partir de la comparación sistemática de casos históricos. Sobre las comparaciones, advierte que es común el error de intentar cotejar fenómenos históricos que tuvieron lugar -a los que denomina "formaciones históricas reales"- con los tipos ideales abstractos $^{1}$ enunciados teóricamente, por lo que sugiere para su análisis la comparación entre dos casos antagónicos contemporáneos, una formación histórica a nivel diacrónico y la constatación de las diferencias entre la retórica y los resultados efectivos de algunas experiencias políticas. Para las comparaciones establece cuatro períodos, definidos a partir de las coyunturas de la política internacional, y cinco ejes, vinculados a aspectos como la ideología, el poder mundial, los regímenes políticos, la economía y las relaciones entre ellos. La relevancia de cada eje varía según el espacio geográfico y la época histórica, pero se rescata la centralidad de América Latina como espacio donde han proliferado las experiencias populistas. Señala además, su preferencia por la categoría "movimientos nacional-populares" para referirse a las experiencias históricas que tuvieron lugar en dicho espacio geográfico, por ser una categoría surgida en el mismo y que refleja acabadamente el influjo que ha tenido el nacionalismo en la mayoría de los casos.

1. Para una definición de estas categorías puede verse BUCHRUCKER, Cristian, Glosario para el estudio de la historia contemporánea, Ediunc, Mendoza, 2010, p. 117. 
Los tres capítulos siguientes se abocan al estudio de los casos históricos y de los debates historiográficos en el espacio latinoamericano. En primer lugar, se plantea una reflexión sobre la relación que han entablado los historiadores con el término y su aporte al debate académico que tiene y ha tenido lugar en las Ciencias Sociales, destacando la importancia de analizar en profundidad y con las herramientas de trabajo que cuenta la disciplina, los contextos de surgimiento de las experiencias populistas al igual que los cambios y continuidades que tienen lugar en las coyunturas históricas que las preceden y las suceden. La autora postula aquí un rol clave para el historiador como "depurador de simpatías", asignándole la tarea de limitar el uso abusivo y las cargas peyorativas. Se presenta luego la periodización que ha establecido la historiografía en relación a los populismos y se enuncia una periodización propia. Asimismo, destaca el rol que cumplen las prácticas políticas y culturales preexistentes en la formación de los populismos y analiza globalmente los casos latinoamericanos ubicándolos en el marco de la evolución de los sistemas políticos y el desenvolvimiento de la economía en la región.

El tercer capítulo profundiza en los factores internos y los condicionamientos externos que posibilitaron el surgimiento de los populismos latinoamericanos, en especial la economía a partir de la crisis de 1930, y las crisis de los sistemas políticos, junto con las problemáticas sociales irresueltas que éstos intentaron conjurar. Asimismo, argumenta que los populismos contienen en su seno una concepción sui generis de la democracia de la participación política que no debe ser deslegitimada por el solo hecho de no avenirse a los postulados de la democracia formal de cuño anglosajón.
El cuarto apartado está abocado al estudio de los casos históricos que tuvieron lugar en Argentina y Brasil, puntualmente de dos casos paradigmáticos de populismo: el peronismo y el varguismo. La autora retoma aquí argumentos enunciados en otra de sus obras ${ }^{2}$ para hacer un recorrido por los debates historiográficos de la década del noventa que tuvieron lugar en torno a cada caso, indagando además sobre las semejanzas y diferencias entre ambos, y las continuidades en el tiempo de ambas experiencias en sus respectivos países. Luego presenta una comparación entre ambos casos para analizar los abordajes historiográficos y las premisas de los intelectuales sobre los mismos. Por último se presentan algunas críticas a las líneas de trabajo más recientes que ponen el foco en aspectos culturales -como el caso de Loris Zanatta ${ }^{3}$ y se postula la necesidad de evitar los preconceptos en torno a la relación entre populismo y democracia, reconociendo que el primero es parte de los procesos de cambio estructural gestados en determinadas coyunturas históricas.

El quinto capítulo presenta un abordaje del populismo en la historia argentina mediante un análisis comparativo que parte de dos ejes: las políticas económicas y las políticas de salud pública. Establece así ocho períodos de análisis -correlativos con los gobiernos que se sucedieron entre 1916 y 1969-, dando un lugar primordial en el análisis a los casos del radicalismo yrigoyenista y el peronismo. Al respecto, señala la existencia de algunas líneas de continuidad entre ambas experiencias, y

2. CARRIZO DE MUÑOZ, Nidia, El silencio de los historiadores. La ausente teoria de la historia Argentina y Brasil, Ediunc, Mendoza, 2010.

3.ZANATTA, Loris, El Populismo, Katz, Buenos Aires, 2014. 
define al primero como un populismo "tibio" y al segundo como uno "profundo". Asimismo, destaca el potencial de cambio histórico de ambos gobiernos y el impacto global de sus políticas en los sectores más relegados de la sociedad argentina.

La obra constituye un interesante aporte al debate académico sobre este controvertido concepto, rescatando el aporte que deben hacer la Historia y los historiadores con su trabajo a las Ciencias Sociales para clarificar su utilización, sobre todo cuando lo que está en disputa son interpretaciones del pasado. Constituye además una invitación a profundizar el análisis histórico de los casos, procurando no condenar de antemano a estas experiencias históricas y comprendiendo que son una manifestación más de las formas en que las sociedades se expresan política, social y culturalmente. Asimismo, la preferencia por la caracterización de estas experiencias históricas en América Latina como "movimientos nacionalpopulares" viene a proponer una herramienta teórica alternativa para los historiadores, que permita superar la carga semántica negativa y la ambigüedad que conlleva hoy el uso de la categoría "populismo", y contemple las notas específicas que estos fenómenos adoptaron en la región.

Recibido: 01-04-2016

Aceptado: 01-06-2016

Publicado: 30-12-2016 